\title{
PEMODELAN POLA ARUS BAROTROPIK MUSIMAN 3 DIMENSI (3D) UNTUK MENSIMULASIKAN FENOMENA UPWELLING DI PERAIRAN INDONESIA
}

\author{
Eva Mustikasari'1), Lestari Cendikia Dewi"1), Aida Heriati'1) \& Widodo Setiyo Pranowo1) \\ 1)Pusat Penelitian dan Pengembangan Sumber Daya Laut dan Pesisir, Balitbang-KP, KKP \\ Diterima tanggal: 10 Januari 2015; Diterima setelah perbaikan: 11 Mei 2015; Disetujui terbit tanggal 24 Juni 2015
}

\begin{abstract}
ABSTRAK
Pemodelan arus barotropik musiman tiga dimensi dilakukan untuk mensimulasikan fenomena upwelling di Perairan Indonesia. Pemetaan upwelling berguna sebagai tahap awal dalam mengetahui daerah potensial penangkapan ikan. Model hidrodinamika yang digunakan dalam studi ini adalah finite volume. Skenario model berupa domain dalam sepuluh lapisan kolom air (equidistant) dengan pembangkit arus berupa angin dan pasang surut. Gaya coriolis dimasukkan dalam perhitungan karena model memiliki domain yang luas. Simulasi dilakukan untuk Januari, April, Agustus dan Oktober 2007. Pola arus tiga dimensi (u, v, w) dan elevasi setiap jam didapat sebagai keluaran. Komponen positif arus vertikal, w, dirata-ratakan sepanjang bulan per elemen kolom air, kemudian di-plot menjadi peta upwelling. Pola arus hasil simulasi dapat menggambarkan eksistensi Halmahera Eddy, Mindanao Eddy, South Java Current, Coastal Kelvin Wave (diduga) dan Arus Lintas Indonesia. Validasi yang baik ditunjukkan dengan galat $R M S$ elevasi relatif rendah, pada dua stasiun buoy DART di wilayah studi, yaitu $5,8542 \times 10^{-2} \mathrm{~m}$ $-1,1735 \times 10^{-1} \mathrm{~m}$. Upwelling pada Musim Barat terjadi di Indonesia Timur (perairan Busur Banda, Laut Maluku, Laut Seram, Selat Ujung Pandang, Teluk Tomini, Teluk Tolo, Teluk Bone). Upwelling mulai muncul di selatan Jawa, sedangkan di Indonesia Timur menjadi berkurang pada Musim Peralihan I. Pada Musim Timur, upwelling mulai muncul dari selatan Jawa sampai barat Sumatera Barat dan menguat di Indonesia Timur. Pada Musim Peralihan II, upwelling meluas ke arah barat sampai perairan Pulau Simeuleu, sedangkan di Indonesia Timur berkurang dibandingkan Musim Timur.
\end{abstract}

Kata kunci: Model Hidrodinamika 3D, Arus Barotrpik, Upwelling, Perairan Indonesia.

\section{ABSTRACT}

A three-dimensional barotropic current modeling is employed to simulate the seasonal upwelling phenomenon in Indonesian seas which is important to the fisheries activity. The model is setup using finite volume as basis function to compute hydrodynamics in a water column which is constructed as ten equidistants sigma layer. 3D velocity and sea level dynamics are simulated for January, April, August and October 2007 using tidal and wind forcing. Coriolis parameter is taken into account since it has large model domain. Upwelling map is derived from average monthly per water column element of positive vertical current component (w). Result shows the presence of Halmahera Eddy, Mindanao Eddy, South Java Current, Coastal Kelvin Wave (suspected) and Indonesian Through-Flow. It has a good validation in sea level time series using DART mooring buoy (RMS error $5.8542 \times 10^{-2} \mathrm{~m}-1.1735 \times 10^{-1} \mathrm{~m}$ ). The west monsoon (January) upwelling is founded in western part of Indonesia (Banda-arc Sea, Maluku Sea, Seram Sea, Makassar Strait, Tomini Bay, Tolo bay, Bone bay). In transition season I (April), upwelling is started to reveal in South Java Sea, while the upwelling intensity in the eastern part of Indonesia is decreasing. During east monsoon (August), a large field and high intensity of coastal upwelling occur in along southern part of Java until western part of Sumatera. Those upwelling field is continue widening to western part of Simeuleu island during the transition II season (October), while in eastern part of indonesia the upwelling field is decreasing during this season.

\section{Keywords: 3D hydrodynamic model, barotropic current, seasonal upwelling, Indonesian seas.}

\section{PENDAHULUAN}

Upwelling adalah pergerakan massa air ke atas permukaan laut yang banyak membawa unsur hara dan memiliki tingkat kesuburan primer yang tinggi. Wilayah perairan laut yang terjadi upwelling merupakan fishing ground yang sangat potensial karena kaya akan zat-zat hara dan nutrien (Ihsan, 2013). Daerah tempat upwelling terjadi biasanya akan membawa massa air yang suhunya lebih rendah, juga membawa zat hara sehingga kesuburan perairan tersebut akan meningkat. Kesuburan suatu perairan diharapkan akan meningkatkan kelimpahan sumber daya hayati perairan tersebut. Pengetahuan tentang lokasi perairan dengan fenomena tersebut akan dapat membantu para nelayan untuk mencari lokasi daerah penangkapan ikan (Simbolon \& Tadjuddah, 2008).
Sunarto (2008) menyatakan bahwa unsur hara yang terbawa dari dasar perairan karena proses upwelling menjadi sumber nutrisi bagi produsen primer di laut yang merupakan sumber energi bagi seluruh konsumen di rantai makanan dalam proses produksi di laut. Upwelling biasanya berada di kisaran kedalaman perairan 200-300 m (Bowden \& Ferguson, 1980), sedangkan Cole \& McGlade (1998) menyatakan bahwa upwelling dapat pula terjadi di perairan yang lebih dangkal dengan kedalaman 20-40 m. Bowden (1983) menyatakan variasi musiman upwelling terjadi berhubungan dengan kekuatan angin. Kemili (2012) juga melakukan penelitian terhadap hubungan fenomena upwelling dan kesuburan wilayah sekitarnya, yaitu dalam hasil penelitiannya dilaporkan bahwa selatan Jawa Timur dan Laut Banda memiliki durasi upwelling yang lebih panjang (3-4 bulan) dan intensitas ensi Penulis: 
yang lebih tinggi (anomali SST mencapai $>-2^{\circ} \mathrm{C}$ dibawah rata-rata) menghasilkan produktivitas primer yang tinggi pula dibandingkan daerah sekitarnya.

Kajian mengenai upwelling sangat menarik untuk dilakukan mengingat fenomena ini menciptakan suatu kondisi yang menguntungkan bagi kegiatan perikanan di Indonesia, seperti penelitian Kunarso (2005) yang melakukan overlay terhadap peta distribusi tuna dan lokasi upwelling sehingga menghasilkan fishing ground tuna yang potensial berdasarkan variasi bulan dan tipe kejadian iklim (Normal, El Niño dan La Niña).

Lokasi pergerakan zona konvergensi sebagai area fishing ground, dapat dipetakan salah satunya dengan cara memodelkan dinamika arus vertikal. Model hidrodinamika 3-D menggunakan ROMS di selatan Benguela telah dilakukan oleh Penven et al. (2001) dengan resolusi yang tinggi di daerah pantai serta melakukan couple model hidrodinamika dan model biologi menggunakan pendekatan model nutrien fitoplankton zooplankton untuk mensimulasikan produksi plankton serta telur dan larva. Liu (1995) menyimpulkan bahwa model yang simpel tidak dapat mensimulasikan dengan baik kecepatan dan percepatan dari kolom air, padahal kedua hal tersebut merupakan faktor penting dalam menentukan laju upwelling. Pada penelitian ini model hidrodinamika yang dibangun mengasumsikan bahwa arus bersifat barotropik, artinya arus diasumsikan dibangkitkan oleh pasang surut (pasut) dan angin namun belum memperhatikan perbedaan temperatur dan densitas. Pemodelan arus tiga dimensi dibangun menggunakan metode numeric finite volume. Hasil dari penelitian ini diharapkan dapat memberikan kontribusi bagi dunia pemodelan oseanografi khususnya pemodelan upwelling yang merupakan fenomena penting bagi dunia perikanan kita.

\section{METODE PENELITIAN}

Simulasi pemodelan dilakukan di wilayah Perairan Indonesia selama Januari, April, Agustus, dan Oktober 2007. Masing-masing bulan berturut-turut mewakili Musim Barat, Musim Peralihan I, Musim Timur dan Musim Peralihan II. Dalam penelitian ini, Perairan Indonesia merupakan objek pemetaan upwelling. Untuk memenuhi kebutuhan itu, pemodelan numerik ini mengambil domain (area pemodelan) lebih luas dari batas wilayah perairan Indonesia. Batas domain meliputi $84,43807^{\circ} \mathrm{BT}-145,6843^{\circ} \mathrm{BT}$ dan $24,6095^{\circ} \mathrm{LS}-$ $22,48639^{\circ} \mathrm{LU}$ serta kedalaman perairan yang dibatasi oleh batimetri. Domain ini dibagi menjadi 10 lapisan dengan equidistance system koordinat sigma $(\sigma=0.1$ atau 1/10). Lapisan ke 1 merupakan lapisan terdalam. Sedangkan, lapisan ke 10 merupakan lapisan terdangkal. Alur teknis pemodelan ditunjukkan pada Gambar 1.

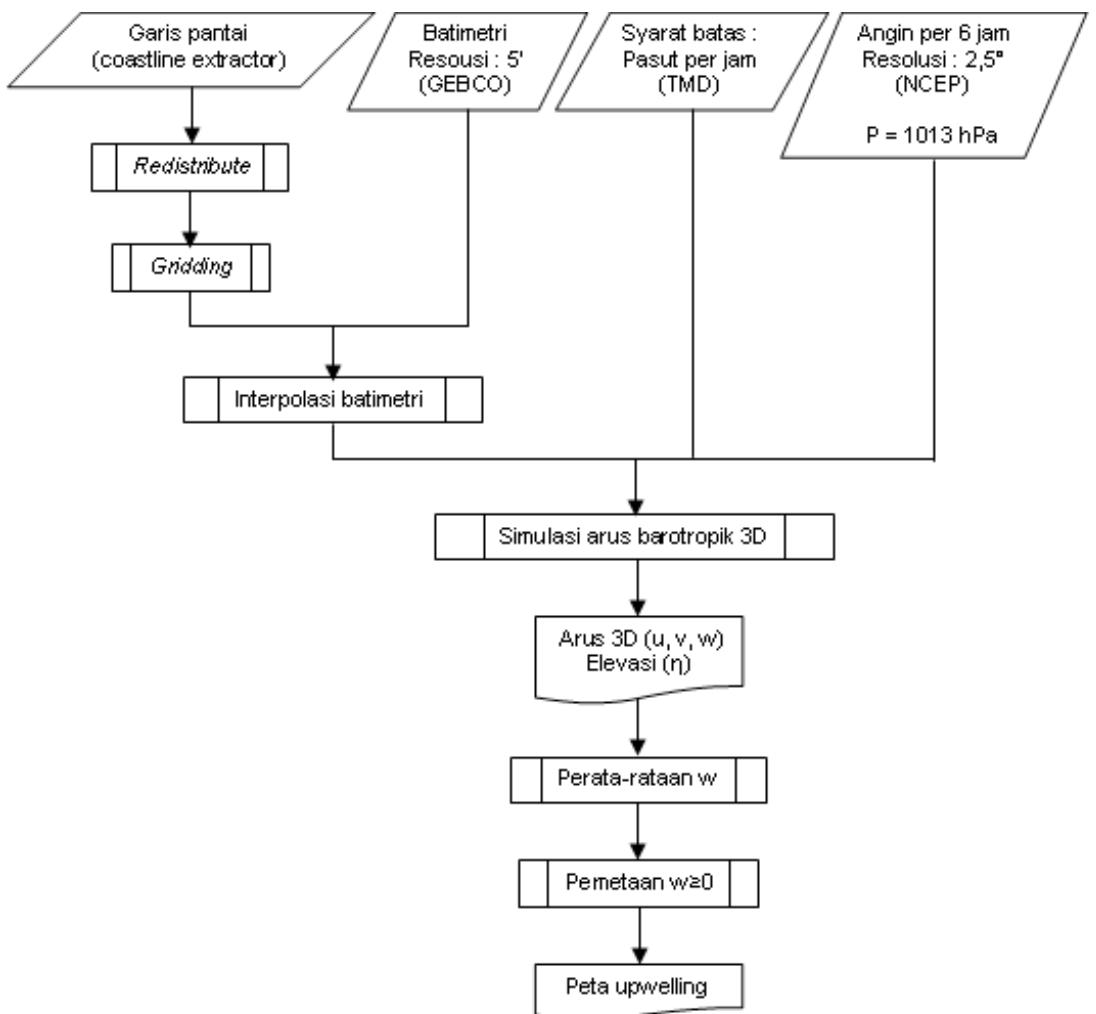

Gambar 1. Diagram alir teknis pemodelan pola arus barotropik 3D untuk mensimulasikan fenomena upwelling. 
Pemodelan hidrodinamika ditempuh dengan pendekatan numeric finite volume (DHI, 2007). Asumsi yang dipakai adalah arus bersifat barotropik. Data batimetri diperoleh dari GEBCO (General Bathymetric Chart of the Ocean) dengan resolusi 5 menit. Data garis pantai diperoleh dari Coastline Extractor. Data pasang surut per jam diperoleh dari TMD atau Tidal Model Driver (Egbert \& Erofeeva, 2002). Data angin per enam jam diperoleh dari NCEP (National Center for Environmental Prediction). Reanalysis data dengan resolusi 2,5 derajat (Kalnay et al., 1996). Tekanan udara di permukaan laut diasumsikan nilainya seragam sepanjang waktu simulasi, yaitu $1.013 \mathrm{hPa}$.

Pemodelan diawali dengan memasukkan batas tertutup, yaitu garis pantai seluruh pulau yang termasuk ke dalam domain model. Selanjutnya garis pantai ini di-redistribute untuk mengatur jarak titik-titik pembentuk garis pantai. Batas terbuka model dibuat di perairan terbuka sehingga domain telah menjadi sistem tertutup. Batas terbuka model ini juga perlu di-redistribute. Diagram alir teknis pemodelan diberikan oleh Gambar 1.

Setelah batas domain di permukaan terbentuk maka langkah selanjutnya adalah melakukan gridding berupa unstructered mesh. Grid berbentuk segitiga yang ukurannya berbeda-beda. Selanjutnya sepanjang batas terbuka dan sepanjang waktu simulasi di-input data pasang surut per jam seperti ditunjukkan pada Gambar 2.

Pembuatan domain model diakhiri dengan meng- input batimetri. Sehingga domain model terbentuk berupa ruang perairan tiga dimensi. Batimetri diinterpolasi terhadap grid yang sudah dibuat. Domain model dan hasil interpolasi ditunjukkan pada Gambar 3.

Data angin per enam jam dan data tekanan permukaan laut digunakan di seluruh permukaan domain model dan sepanjang waktu simulasi. Data angin rata-rata pada Januari, April, Agustus dan Oktober 2007 ditunjukkan pada Gambar 4. Pengolahan data angin dilakukan dengan menggunakan perangkat lunak dan modul panduan yang dikembangkan oleh Setiawan (2007).

Hasil simulasi berupa arus tiga dimensi dan elevasi tiap jam selama waktu simulasi di setiap lapisan domain model. Arus terdiri dari tiga komponen yaitu u dan $v$ mewakili arus horisontal dan $w$ mewakili arus vertikal. Agar dapat memetakan fenomena upwelling bulanan, maka dilakukan perata-rataan komponen arus vertikal (w). Perata-rataan ini meliputi peratarataan komponen w sepanjang waktu simulasi dan sepanjang kolom air.

Arus vertikal (w) memiliki nilai positif dan negatif. Komponen arus $w$ positif berarti arah arus ke atas, yang dikenal dengan upwelling. Komponen arus w negatif berarti arah arus ke bawah, yang dikenal dengan downwelling. Selanjutnya, dilakukan pemetaan arus vertikal bernilai positif $(w \geq 0)$. Sehingga, peta upwelling rata-rata untuk setiap bulan diperoleh yaitu Januari, April, Agustus dan Oktober 2007.
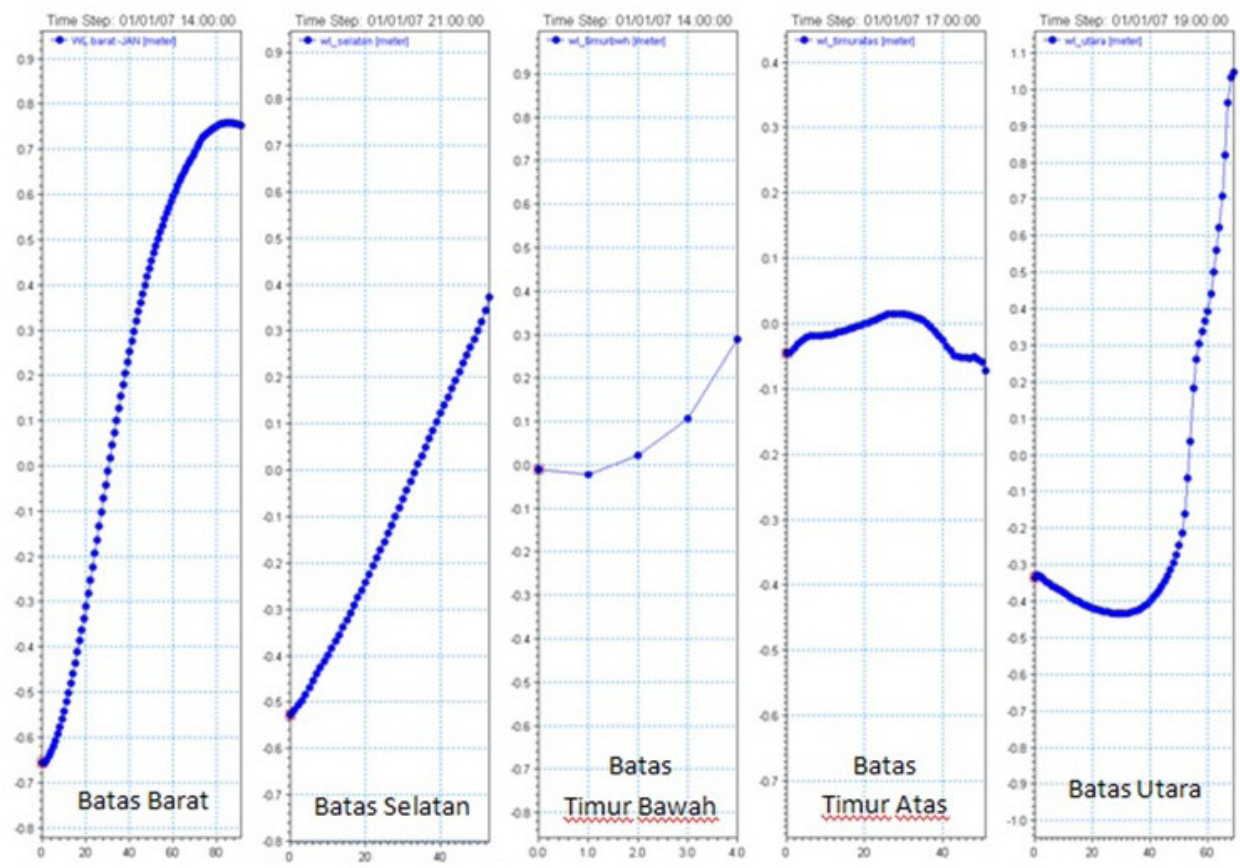

Kode nomor batas:

1. Batas tertutup

2. Batas Barat

3. Batas Selatan

4. Batas Timur Bawah

5. Batas Timur Atas

6. Batas Utara

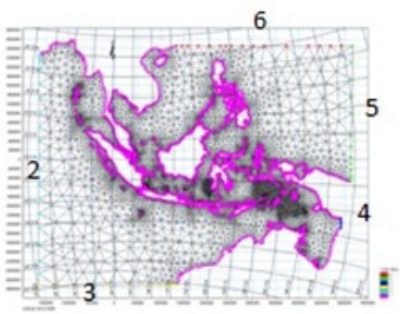

Gambar 2. Gridding dan input data pasut sebagai syarat batas terbuka domain model. 


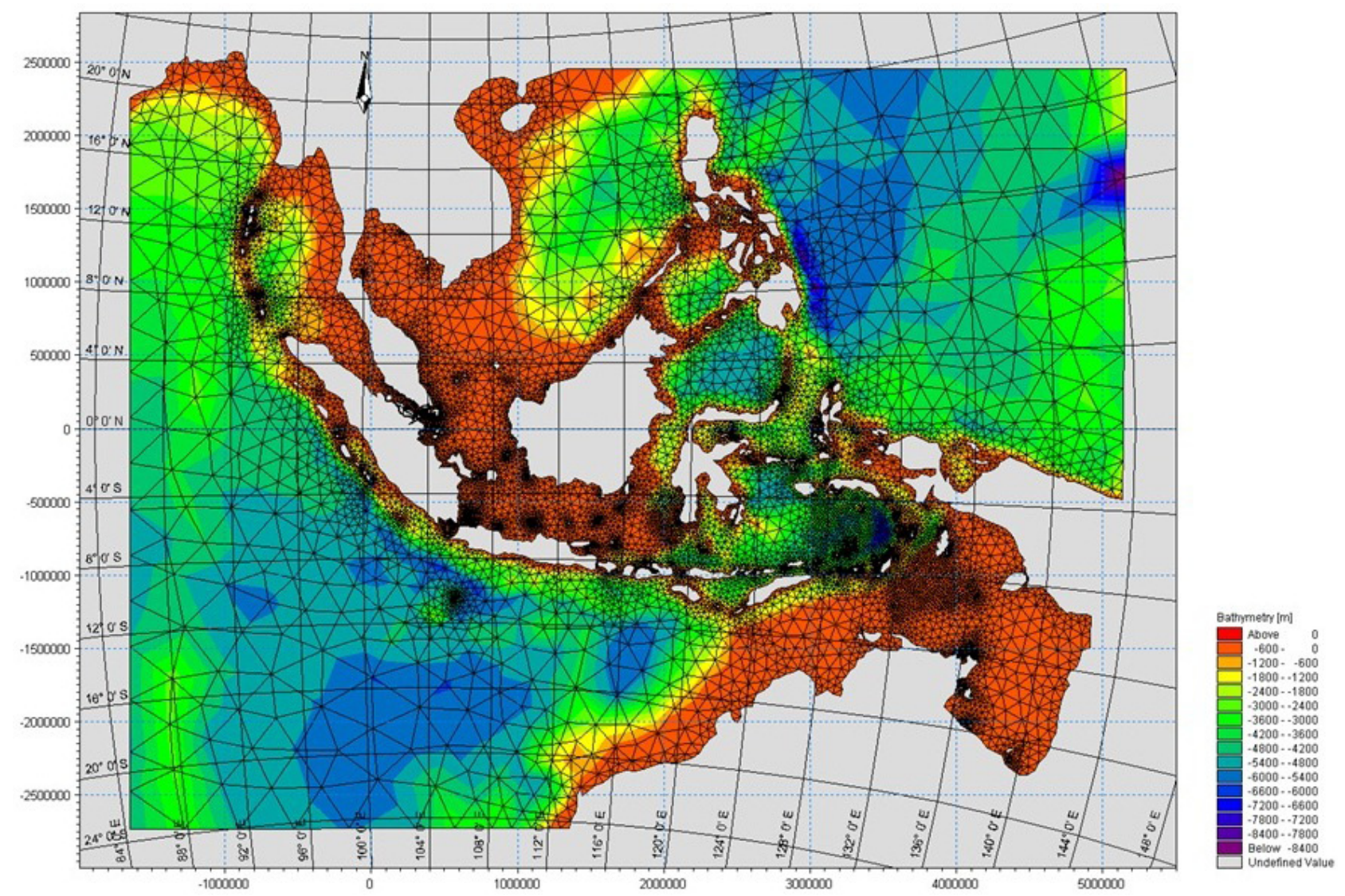

Gambar 3. Interpolasi batimetri domain model.

\section{HASIL DAN PEMBAHASAN}

Pada umumnya pola arus yang dibangkitkan oleh pasang surut dan angin memperlihatkan bahwa pergerakan arus mengikuti pola pergerakan pasang surut (Gambar 5). Kecepatan arus pada waktu pasang purnama (spring) lebih besar dari pada waktu perbani (neap).

\section{A. Pola angin musiman di perairan Indonesia}

Pola pergerakan arus di perairan Indonesia sangat dipengaruhi oleh angin musim. Angin bertiup bergantian sepanjang tahun sebagai dampak dari perubahan musim yang terjadi di Benua Asia dan Benua Australia (Gambar 4). Pada Januari, angin bertiup dari timur laut, yaitu Samudera Pasifik, ke arah barat daya dan berbelok di Indonesia dari barat ke timur dan dikenal sebagai musim barat (DesemberFebruari). Pada Agustus, angin bertiup dari tenggara, yaitu Australia, ke arah barat laut melewati Indonesia, dan berbelok ke arah timur laut di utara katulistiwa. yang dikenal sebagai Musim Timur (Juni-Agustus). Musim Barat ditandai oleh musim hujan dan kerasnya angin bertiup, sedangkan musim Timur ditandai oleh musim kemarau dan kecepatan angin cenderung melemah. Berbeda dengan dua musim utama, pada Maret-Mei dan September-November, arah kecepatan angin berfluktuasi sehingga dinamakan musim transisi atau musim peralihan. Pada April (Musim Peralihan 1), baik di utara maupun di selatan Indonesia, angin bergerak ke arah barat, dan di atas wilayah Indonesia angin menjadi melemah. Pada Oktober (Musim Peralihan II), angin dari timur laut, yaitu Samudera Pasifik, bergerak ke arah barat daya dan bertemu dengan angin yang berhembus dari tenggara, yaitu Australia ke arah barat laut. Sehingga pada wilayah Indonesia, angin ini menjadi melemah.

\section{B. Pola Pergerakan Pasang Surut}

Keluaran dari pemodelan arus barotropik 3D ini berupa arus horisontal $(u, v)$, arus vertikal $(w)$ dan elevasi setiap jam selama Januari, April, Agustus dan Oktober 2007. Bahan diskusi dalam pembahasan ini adalah cuplikan hasil simulasi tersebut, yaitu simulasi arus di perairan Indonesia saat Teluk Jakarta mengalami pasang surut purnama pada Oktober 2007 (Gambar 5).

Saat Teluk Jakarta menuju pasang, nampak elevasi Teluk Jakarta sampai perairan Belitung mendekati nol. Sementara itu, perairan di sekitarnya, yaitu utara Belitung dan selatan Kalimantan memiliki elevasi lebih tinggi. Pola arus horisontal di kedua perairan itu saling mendekati karena bergerak menuju 

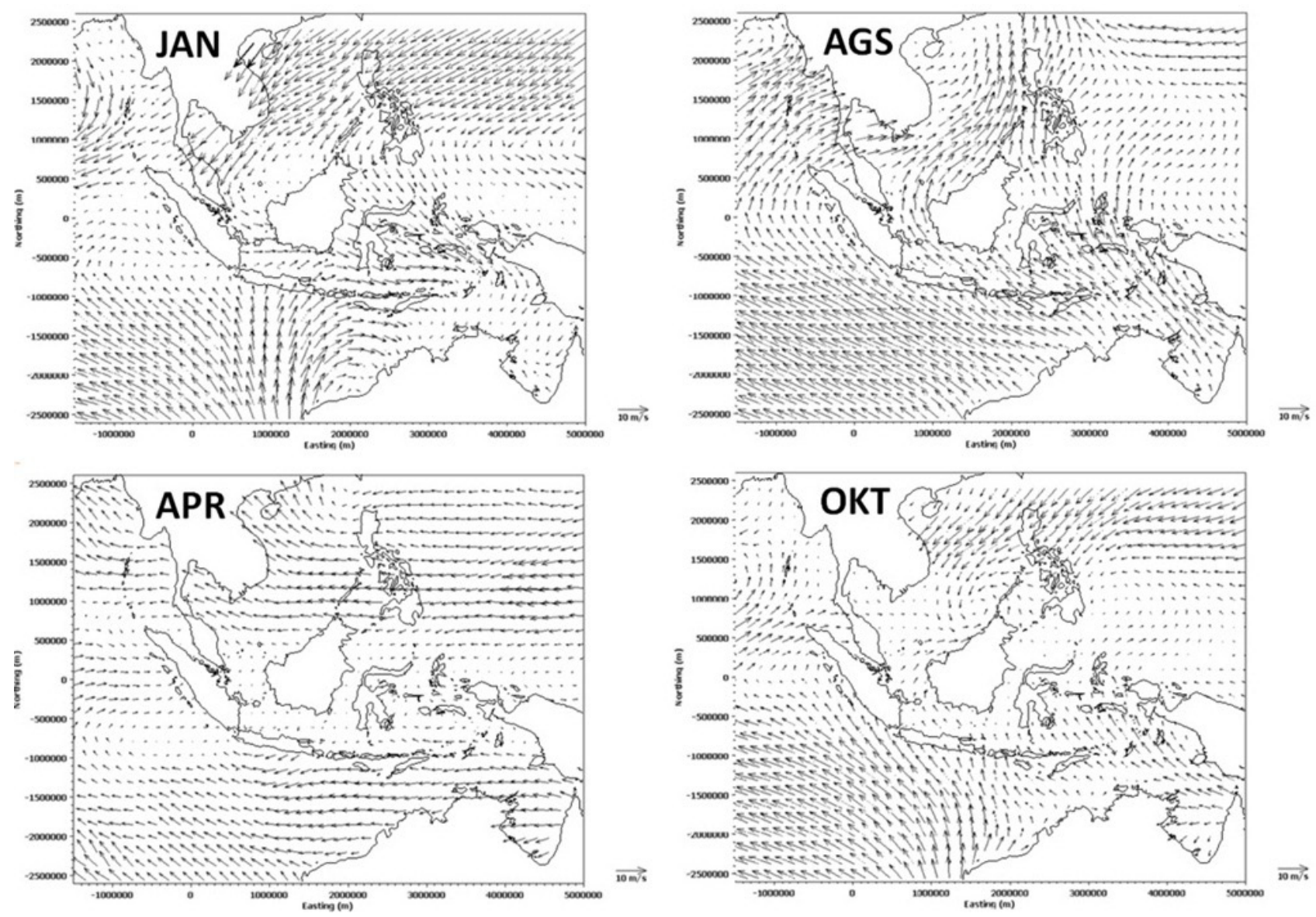

Gambar 4. Data angin rata-rata per bulan (2007), diolah berdasarkan dari data NCEP Reanalysis.

elevasi yang lebih rendah. Sementara itu, perairan di Indonesia timur (L. Flores, L. Banda, L. Sulawesi, Selat Makasar) sedang mengalami surut (berwarna biru).

Saat Teluk Jakarta pasang tertinggi, nampak elevasi Teluk Jakarta sampai perairan Belitung mencapai elevasi yang lebih tinggi dibandingkan dengan perairan di selatan Kalimantan dan Laut Cina Selatan. Pola arus horisontal di Teluk Jakarta pun masih sama yaitu arus saling mendekati yang menyebabkan pengumpulan massa air hingga berelevasi lebih tinggi dari sekitarnya. Sementara Selat Makassar, L. Sulawesi dan Samudera Pasifik sedang mengalami pasang (berwarna hijau).

Saat Teluk Jakarta menuju surut, perairan Belitung masih pasang dan lebih tinggi elevasinya dibandingkan bagian utara dan bagian tenggara termasuk Teluk Jakarta. Arah arus menjauhi perairan Belitung yaitu ke bagian tenggara dan bagian utara yang memang menunjukkan elevasi lebih rendah (berwarna biru). Perairan lainnya di wilayah studi masih pasang kecuali L. Andaman dan barat daya Papua.

Saat Teluk Jakarta surut terendah, nampak elevasinya lebih rendah bersama dengan perairan
Belitung. Arah arus di utara Jakarta adalah ke barat karena perairan di timur Teluk Jakarta berelevasi lebih tinggi. Sementara itu perairan lainnya di Indonesia masih pasang dan Samudera Pasifik sudah surut.

\section{Pola Arus vertikal Musiman sebagai Indikasi upwelling di Perairan Indonesia}

Pengaruh angin dan pasang surut sangat menentukan besar dan arah arus secara horisontal. Sementara keadaan topografi sangat menentukan arah arus vertikal. Agar memudahkan mendeskripsikan upwelling musiman, maka nilai arus vertikal (w) dirataratakan setiap bulan sepanjang waktu simulasi dan sepanjang seluruh lapisan kolom air. Nilai positif hasil rata-rata tersebut kemudian dipetakan secara spasial sehingga diperoleh perbedaan kondisi upwelling tiap musim (Gambar 6).

Musim Barat (Januari 2007), upwelling di Perairan Indonesia bagian barat nampak minim. Sedangkan di bagian timur muncul upwelling. Di perairan Sumatera terhitung tidak ada upwelling kecuali di sekitar Pulau We dengan tingkat lemah sampai kuat. Di perairan sekitar Pulau Jawa terhitung tidak ada upwelling. Penelitian dari Susanto et al. (2001) melaporkan bahwa 
kondisi upwelling di sekitar pantai Jawa dan Sumatera dipengaruhi oleh kondisi angin lokal dan interaksi lautatmosfer secara global yang berhubungan dengan ENSO. Sementara di sekitar Pulau Kalimantan hanya ada upwelling di perairan sebelah timur yaitu di Selat Ujung Pandang antara Teluk Sangkurilang sampai Tanjung Aru dengan tingkat lemah sampai kuat dan relatif luas. Di perairan sekitar Pulau Sulawesi, upwelling lemah sampai kuat dan relatif luas muncul di perairan Teluk Tomini bagian utara dan barat, Teluk Tolo sampai timur laut Pulau Butung dan Tanjung Pangkalang, timur Pulau Peleng, serta perairan Teluk Bone bagian barat. Upwelling juga muncul di sekitar Kepulauan Talaud dengan tingkat kuat namun sempit areanya.

Perairan sekitar Pulau Bali, upwelling dominan lemah ada di bagian utara, dan kuat di Selat Balung. Upwelling muncul dominan kuat di utara, barat dan selatan Pulau Lombok. Upwelling lemah sampai kuat terdapat di utara Pulau Sumbawa sampai Selat Sape. Upwelling dominan kuat juga muncul di utara Pulau Flores, Adonara, Siantar, Alor, Sumba, Timor.
Upwelling lemah muncul di Laut Sawu dengan area relatif luas sampai di perairan sekitar Pulau Roti dan Pulau Sawu.

Laut Banda terlihat upwelling lemah dengan area luas. Sementara di pulau sekitarnya, upwelling muncul di utara Pulau Wetar dengan tingkat kuat dan relatif sempit. Selain itu, upwelling cukup luas berada di sekitar Kepulauan Kai. Upwelling dominan kuat dan luas ada di Laut Seram sekitar timur laut Pulau Seram sampai tenggara Kepulauan Sula, serta utara dan timur laut Pulau Buru. Di utara Kepulauan Sula juga muncul upwelling yang meluas sampai perairan Bitung. Di sekitar Halmahera, upwelling kuat dan luas muncul di timur dan selatan, yaitu tepatnya di Teluk Weda, Teluk Bull sampai sekitar Tanjung Perak.

Pada perairan Pulau Irian Jaya, upwelling dominan kuat ada di barat Teluk Cenderawasih sekitar Manokwari. Upwelling juga muncul di sekitar Pulau Waigeo, yaitu sebelah timur dengan tingkat kuat, dan bagian barat dengan tingkat dominan lemah.
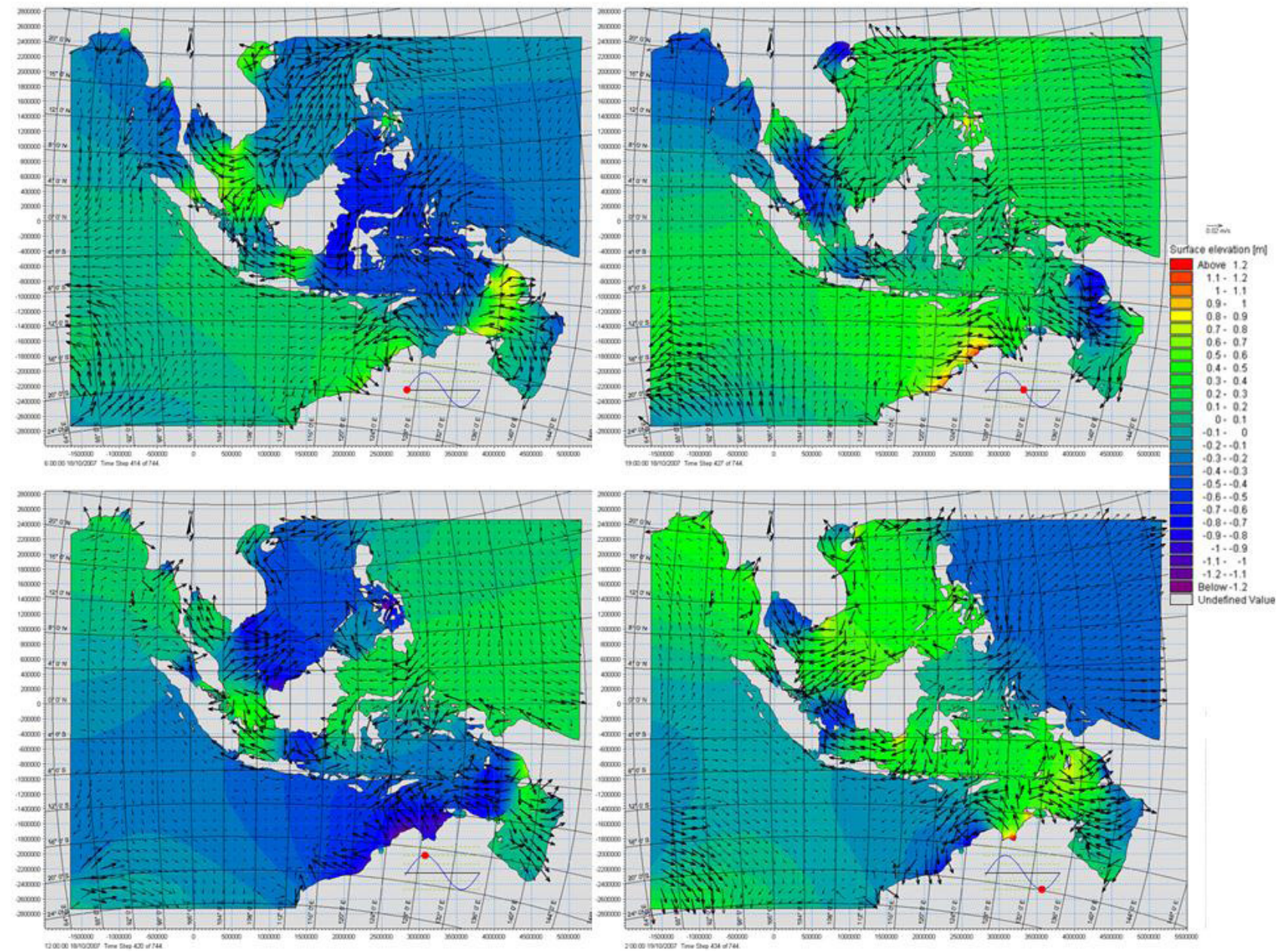

Gambar 5. Contoh simulasi arus horisontal rata-rata (anak panah) dan elevasi permukaan laut (warna) pada Oktober 2007 saat Teluk Jakarta akan pasang (kiri atas), pasang tertinggi (kiri bawah), akan surut (kanan atas), surut terendah (kanan bawah) kondisi purnama. 

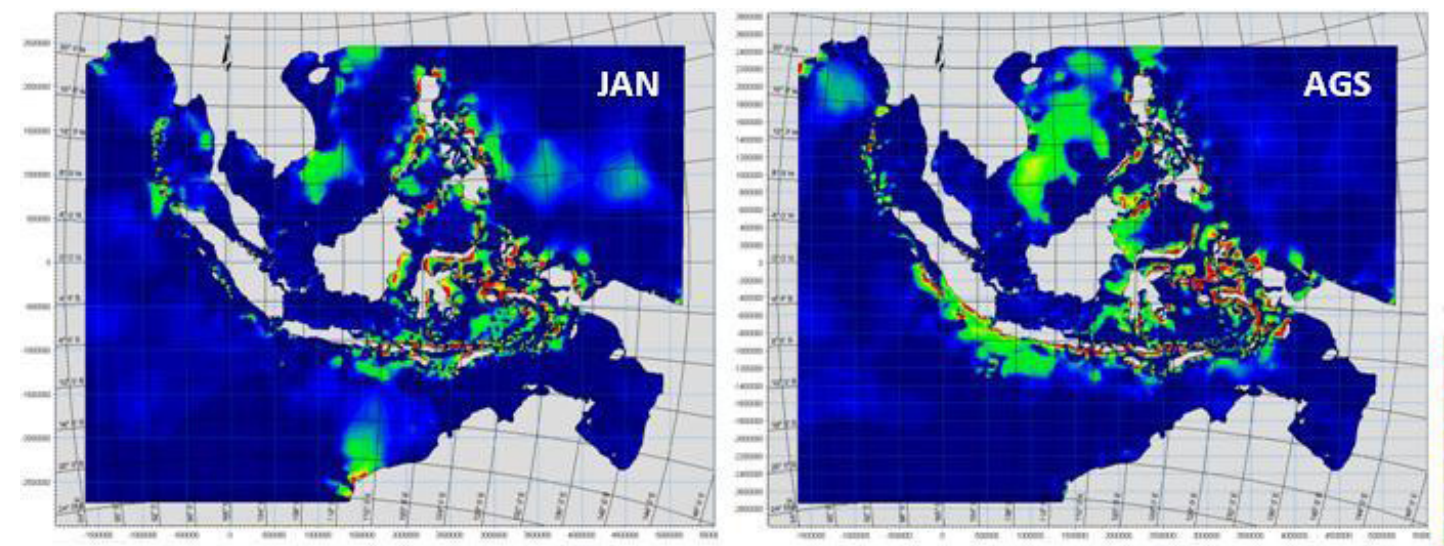

Statistical mean : W velocity [m/s]
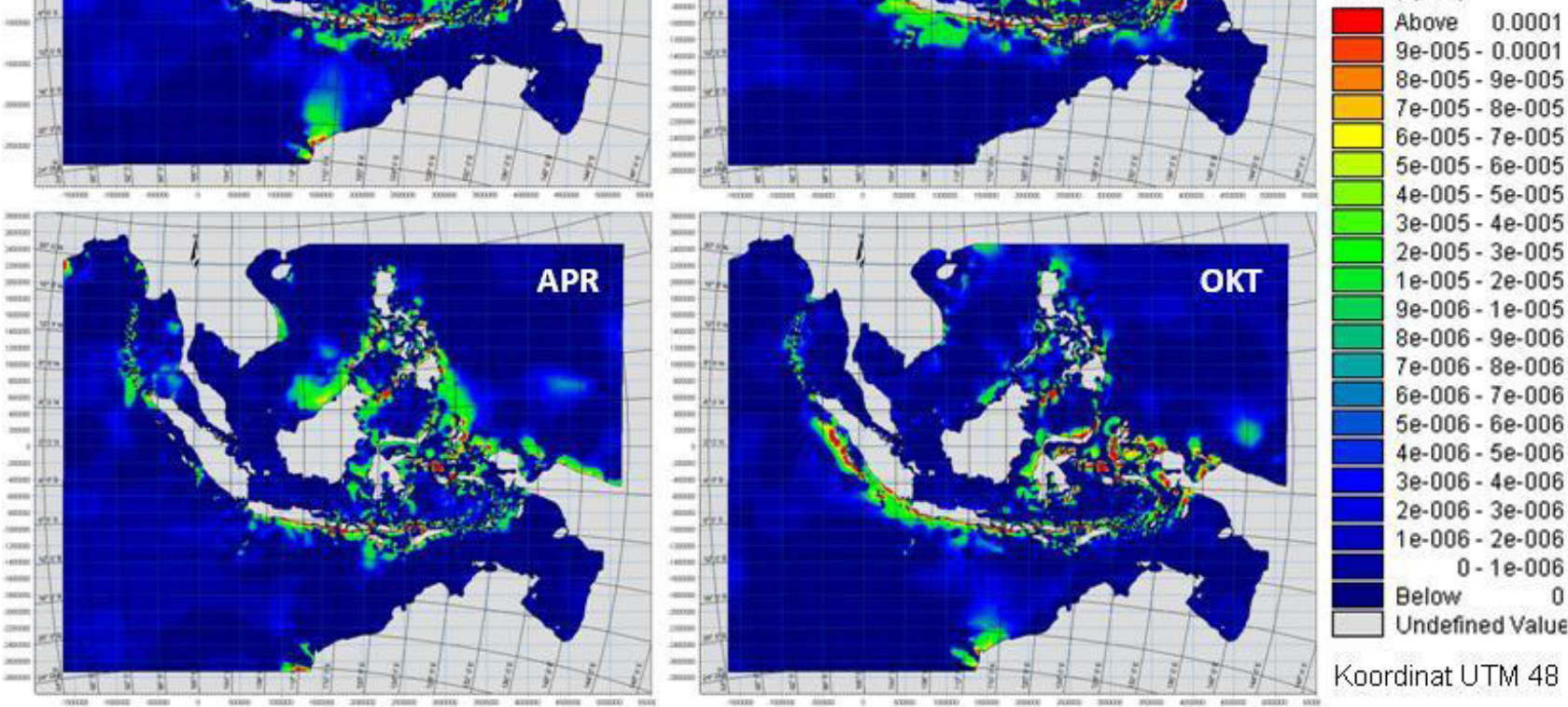

Gambar 6. Peta upwelling rata-rata pada 2007 hasil pemodelan per Januari (kiri atas), April (kiri bawah), Agustus (kanan atas) dan Oktober (kanan bawah).

Musim Peralihan I (April 2007), terjadi perubahan yaitu selatan Jawa mulai ada upwelling dengan tingkat kuat dan dominan lemah dan area relatif luas. Sementara, di sekitar Sumatera tidak ada upwelling kecuali di barat Daerah Istimewa Aceh dengan tingkat dominan lemah. Di perairan kawasan Timur Indonesia kemunculan upwelling menjadi berkurang dibandingkan dengan Musim Barat.

Di perairan sekitar Kalimantan, upwelling terhitung tidak ada, hanya muncul lemah di tengah Selat Makassar. Sementara di sekitar Sulawesi, upwelling umumnya lemah, yaitu di Teluk Tomini bagian utara dan Teluk Tolo. Sementara di Kepulauan Talaud, upwelling dominan lemah juga muncul. Upwelling kuat muncul antara Pulau Peleng dan Pulau Taliabu, dan antara Pulau Wowoni dan Pulau Butung. Upwelling di sekitar Bali dan Nusa Tenggara, pada Musim Barat, banyak yang muncul di sebelah selatan. Upwelling kuat muncul di selatan Pulau Bali dengan area luas. Area upwelling yang luas di sekitar perairan ini juga menguatkan hasil penelitian yang menyatakan bahwa perairan laut selatan NTB hingga Jawa Timur memiliki produktivitas primer yang tinggi dan sangat potensial sebagai daerah fishing effort, mengingat di lokasi ini mengalami upwelling yang paling lama periodenya dan paling tinggi intensitasnya (Kunarso, 2005; Kemili, 2012). Lalu muncul pula upwelling lemah sampai kuat di barat dan selatan Pulau Lombok, Pulau Sumbawa sampai Selat Sape, selatan Pulau Flores, Sumba dan Timor. Upwelling dominan kuat muncul di utara dan selatan Pulau Adonara, Siantar dan Alor.

Di sekitar Laut Banda, upwelling terlihat tidak muncul, hanya ada di pulau-pulau di sekitarnya dengan tingkat lemah dan sempit. Upwelling lemah yang luas ada di antara Pulau Yamdena dan Kepulauan Aru. Upwelling kuat dan relatif luas muncul di antara Pulau Buru dan Pulau Seram, serta di utara dan selatan Kepulauan Sula. Di sekitar Pulau Halmahera muncul upwelling di timur, yaitu sekitar Tanjung Perak dengan tingkat kuat dan luas. Sementara, di Teluk Weda muncul upwelling dominan lemah dengan area luas. Kemunculan upwelling juga terlihat di timur laut Pulau Morotai.

Di perairan Irian Jaya, tingkat upwelling juga lemah yang kemunculannya ada di antara Pulau Misol dan Pulau Seram, di sekitar Pulau Waigeo sampai Sorong, yaitu di Selat Dampit. Upwelling lemah juga muncul di utara Pulau Biak dan di utara Tanjung Darwilis sampai utara Jayapura.

Musim Timur (Agustus 2007) terjadi perubahan keadaan upwelling dibandingkan dengan musim sebelumnya yaitu Musim Peralihan I. Di selatan Jawa 
terlihat upwelling dominan lemah yang lebih luas mencapai Samudera Hindia, sementara tingkat kuat hanya ada di sekitar pesisir selatan Jawa. Upwelling lemah sampai kuat ini juga meluas sampai perairan di barat Lampung dan menerus sampai barat Sumatera Barat tepatnya di Teluk Bayur. Kemunculan upwelling lemah sampai kuat juga meluas dari sekitar Pulau Enggano sampai barat Kepulauan Pagai, Pulau Sipora dan Pulau Siberut serta Kepulauan Batu. Di perairan antara Kalimantan dan Sulawesi muncul upwelling lemah yang relatif luas. Sementara, di sekitar Pulau Sulawesi muncul upwelling lemah sampai kuat relatif luas di utara Sulawesi utara, yaitu di Laut Sulawesi tepatnya di antara Tanjung Kandi sampai Teluk Amurang. Upwelling kuat ada di timur Kepulauan Talaud. Di Teluk Tomini, muncul upwelling dominan kuat dan luas dari utara Tanjung Pangkalsiang sampai Teluk Poso. Di Sulawesi Tenggara, upwelling dominan kuat muncul di timur Pulau Wowoni sampai Tanjung Butung, juga ada di selatan Pulau Butung dan Pulau Muna. Upwelling relatif lemah dan luas ada di Teluk Bone. Upwelling kuat dan luas ada di utara, barat dan selatan Pulau Salayar.

Di Bali dan Nusa Tenggara, upwelling dominan kuat muncul di selatan Pulau Bali, selatan dan barat Pulau Lombok, selatan Pulau Sumbawa sampai Selat Sape. Hal ini sesuai dengan hasil penelitian dari Ningsih (2013) dengan menggunakan data temperatur dan klorofil dari data satelit yang melaporkan bahwa upwelling di sekitar perairan selatan Bali dan Nusa Tenggara kuat terjadi pada periode Juni-Oktober. Upwelling kuat juga muncul di selatan Pulau Flores, Sumba, Sawu, Roti, Timor, utara dan selatan Pulau Adonara, Siantar dan Alor. Kemunculan Upwelling pada musim timur di Laut Sawu ini sesuai dengan hasil pengamatan INSTANT Cruise oleh Puti et al. (2006). Upwelling di Laut Banda muncul di selatan Pulau Wetar dan di sekitar Kepulauan Banda. Upwelling kuat dan luas ada di antara Kepulauan Kai sampai Pulau Seram. Selain itu, di barat Pulau Yamdena muncul upwelling kuat yang luas. Di sekitar Pulau Seram baik utara, barat dan selatan terlihat ada upwelling kuat yang luas, dan juga ada di selatan Pulau Buru. Upwelling kuat juga meluas dari Pulau Seram sampai Pulau Misol. Upwelling kuat muncul pula di selatan dan utara Kepulauan Sula meluas ke barat Kepulauan Obi dan barat Pulau Kasiruta. Upwelling kuat juga meluas dari tenggara Pulau Halmahera sampai Pulau Misol. Sekitar Pulau Halmahera terlihat upwelling kuat dan luas di Teluk Bull Sampai Tanjung Perak menerus sampai selatan Selat Morotai. Upwelling kuat juga muncul di perairan antara Pulau Waigeo dan Pulau Halmahera.

Pada wilayah Irian Jaya, upwelling kuat muncul di utara Pulau Waigeo sampai utara Sorong. Upwelling lemah sampai kuat muncul di barat Fakfak sampai
Tanjung Papisol. Upwelling lemah ada di Teluk Cenderawasih, utara Pulau Biak dan utara Pulau Yapen.

Pada Musim Peralihan II (Oktober 2007), upwelling lemah sampai kuat muncul di selatan Jawa, namun tidak seluas Musim Timur. Sedangkan upwelling di barat Sumatera semakin meluas ke utara. Upwelling lemah sampai kuat muncul dari selatan Jawa sampai barat Sumatera Barat, tepatnya barat Teluk Bayur. Selain itu, upwelling juga meluas dari perairan sekitar Pulau Enggano, barat Kepulauan Mentawai, Kepulauan Batu, Pulau Nias dan Pulau Simeulue. Bersesuaian dengan hasil yang diperoleh Kunarso (2005) yang menyatakan bahwa upwelling di barat Kepualuan Mentawai terjadi secara periodik pada pergantian musim Timur ke Barat hingga Musim Barat saat kondisi normal dan El Niño. Sementara di sekitar Kalimantan terlihat tidak ada upwelling.

Di perairan sekitar Sulawesi, upwelling lemah dominan kuat muncul di utara Sulawesi Utara tepatnya antara Tanjung Kandi sampai TelukAmurang. Upwelling kuat muncul pula di Kepulauan Talaud. Sementara di Selat Makassar muncul upwelling dominan lemah di barat Sulawesi menguat mendekati daratan. Upwelling kuat muncul di Teluk Tomini bagian selatan antara Tanjung Pangkalsiang sampai Teluk Poso. Upwelling kuat masih muncul di timur antara Pulau Wowoni dan Butung. Selain itu, muncul pula upwelling di selatan Pulau Butung dan Kabaena. Upwelling lemah dominan kuat muncul di Selat Selayar. Di Teluk Bone muncul upwelling lemah sampai kuat yang relatif sempit di barat Tanjung Ponopono.

Upwelling masih muncul dominan kuat dan luas di selatan Pulau Bali dan Lombok. Sementara upwelling lemah sampai kuat muncul di selatan Pulau Sumbawa, Selat Sopo, selatan Pulau Flores, utara dan selatan Pulau Andonara sampai Alor., Di utara Pulau Timor, upwelling sangat lemah. Sementara di Laut Banda minim sekali kemunculan upwelling, yang nampak dominan adalah di antara Kepulauan Kai dan Pulau Seram. Di selatan Pulau Seram muncul upwelling lemah sampai kuat. Sementara di antara Pulau Buru dan Seram ada upwelling yang kuat. Upwelling kuat juga muncul di utara dan selatan Kepulauan Sula. Upwelling dominan kuat dan relatif luas ada di selatan Kepulauan Obi sampai barat Pulau Halmahera. Upwelling luas dan dominan lemah ada di antara Pulau Halmahera dan Pulau Misol.

Di Irian Jaya, ada upwelling yang relatif luas dari tingkat lemah sampai kuat. Kemunculannya antara Kepala Burung sampai utara Pulau Waigeo menerus sampai perairan antara Pulau Waigeo dan Pulau Halmahera. Selain itu, muncul juga upwelling lemah sampai kuat di utara Fakfak meluas sampai 

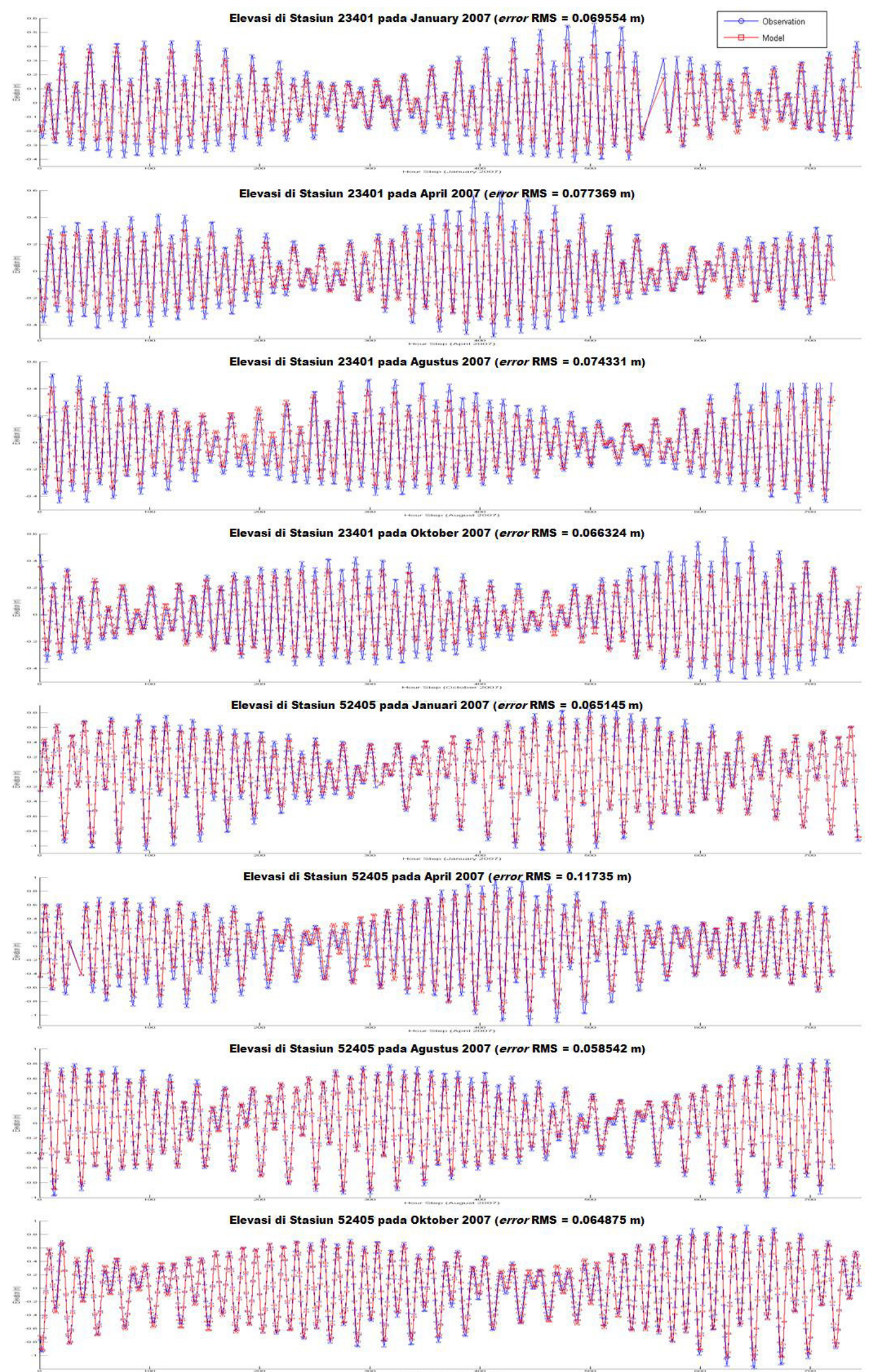

Gambar 7. Elevasi observasi dan model selama Januari, April, Agustus dan Oktober 2007 pada Stasiun DART 23401 dan 52405. 
Tabel 1.

Galat RMS elevasi observasi dan elevasi simulasi

\begin{tabular}{lll}
\hline Bulan & Stasiun 23401 & Stasiun 52405 \\
\hline Januari 2007 & 0,069554 & 0,065145 \\
April 2007 & 0,077369 & 0,117350 \\
Agustus 2007 & 0,074331 & 0,058542 \\
Oktober 2007 & 0,066324 & 0,064875 \\
\hline
\end{tabular}

selatan Tanjung Papisol, juga ada di selatan Pulau Adi, dan di antara Kepulauan Aru dan Tanjung Namaripi. Upwelling lemah sampai kuat dan relatif luas muncul di perairan Cenderawasih, di selatan Pulau Yapen dan antara Tanjung Darwilis dan Pulau Biak, serta timur laut Pulau Biak.

\section{Validasi}

Validasi dilakukan dengan data observasi yang diperoleh dari DART (National Data Buoy Center, National Oceanic and Atmospheric Administration). Ada beberapa stasiun pengamatan di domain model, namun hanya dua stasiun yang memiliki time series yang sama dengan waktu simulasi, yaitu Stasiun 23401 dan 52405. Stasiun 23401 berada di posisi $88.54^{\circ} \mathrm{BT}$, $8.905^{\circ} \mathrm{LU}$ dimiliki oleh Thailand Meteorological Department (TMD). Stasiun 52405 berada di posisi $132.333^{\circ} \mathrm{BT}, 12.881^{\circ} \mathrm{LU}$, dimiliki oleh National Data Buoy Center.

Hasil validasi ditunjukkan oleh Tabel 1 dan Gambar 7. Validasi ini menunjukkan bahwa elevasi model sudah mendekati elevasi observasi, dengan galat RMS elevasi relatif kecil (Pranowo et al., 2010), yaitu antara $5,8542 \times 10^{-2} \mathrm{~m}-1,1735 \times 10^{-1} \mathrm{~m}$. Ini berarti kesalahan elevasi model rata-rata terhadap elevasi observasi tidak lebih dari $11,735 \mathrm{~cm}$.

\section{KESIMPULAN}

Pola arus barotropik 3 dimensi dengan metode finite volume, konsistensinya semakin baik di daerah perairan terbuka, jauh dari pantai. Pola arus hasil simulasi dapat menggambarkan eksistensi Halmahera Eddy, Mindanao Eddy, South Java Current, Coastal Kelvin current, dan Arus Lintas Indonesia. Validasi elevasi muka laut terhadap DART mooring buoy menunjukkan hasil yang memuaskan (Galat RMS elevasi $\left.5,8542 \times 10^{-2} \mathrm{~m}-1,1735 \times 10^{-1} \mathrm{~m}\right)$. Upwelling pada Musim Barat terjadi di Indonesia Timur (perairan Busur Banda, Laut Maluku, Laut Seram, Selat Makassar, Teluk Tomini, Teluk Tolo, dan Teluk Bone). Upwelling mulai muncul di selatan Jawa, pada Musim Peralihan I sedangkan di Indonesia Timur menjadi berkurang. Pada Musim Timur, upwelling mulai muncul dari selatan Jawa sampai barat Sumatera Barat dan menguat di Indonesia Timur. Pada Musim Peralihan II upwelling meluas ke arah barat sampai perairan Pulau Simeuleu, sedangkan di Indonesia Timur berkurang dibandingkan Musim Timur.

Pola arus barotropik 3D dengan metode finite volume dapat menggambarkan kondisi arus di perairan terbuka dengan baik dan sedikit kesalahan. Peningkatan akan keakuratan hasil pemodelan dapat dilakukan dengan menambahkan parameter temperatur dan densitas dalam input model. Lokasi upwelling yang telah diperoleh dari hasil pemodelan ini dapat digunakan sebagai acuan dalam membuat peta lokasi fishing ground di Indonesia.

\section{PERSANTUNAN}

Penelitian ini didanai APBN DIPA TA. 2010 pada Pusat Penelitian dan Pengembangan Sumberdaya Laut dan Pesisir. Penyusunan dan penerbitan manuskrip artikel ini didanai dari sumber yang sama untuk kegiatan "Kajian Perubahan Monsun di Perairan Indonesia (MOMSEI)" TA 2013. Manuskrip artikel ini telah dipresentasikan pada PIT-X ISOI November 2013. Para penulis mengucapkan terima kasih kepada para mentor pemodelan numerik hidrodinamika: Dr. Eng. Nining Sari Ningsih (ITB) dan Dr.rer.nat. Agus Setiawan (BPOL, Badan Litbang KP).

\section{DAFTAR PUSTAKA}

Bowden, K.F. (1983). Physical Oceanography of Coastal Waters. E. Horwood Series in Marine Science, Halsted Press, New York, 302 pp.

Bowden, K.F, \& Ferguson, S.R. (1980). Variations with height of turbulence in a tidally-induced bottom boundary layer. In: J.C.J. Nihoul (Editor), Marinee Turbulence, Elsevier, Amsterdam, p. 259-286.

Cole, J., \& McGlade, J. (1998). Clupeoid population variability, environment \& satellite imagery in coastal upwelling systems. Rev. Fish Biol. Fish. Vol. 8, p. 445-471.

DHI. (2007). Hydrodynamic Module, Scientific Documentation, $58 \mathrm{pp}$.

Egbert, G.D., \& Erofeeva, S. Y. (2002). Efficient Inverse 
Modeling of Barotropic Ocean Tides, Am. Met. Soc. (19): 183-204.

Ihsan, Pemodelan Konseptual Upwelling terhadap target spesies ikan dan teknologi penangkapan ikan. (2013). Dalam http://ptmadanimultikreasi. com. Pada tanggal 8 juni 2015, jam 11.28 WIB.

Kalnay, E., Kanamitsu, M., Kistler, R., Collins, W., Deaven, D., Gandin, L., Iredell, M., Saha, S., White, G., Woolwn, J., Zhu, Y., Chelliah, M., Ebisuzaki, W., Higgins, W., Janowiak, J., Mo, K.C., Ropelewski, C., Wang, J., Leetma, A., Reynold, R., Jenne, R. \& Joseph, D. (1996). The NCEP/ NCAR 40-year Reanalysisi Project, Bull. Am. Met. Soc., 77(3), 437-471.

Kemili, P. \& Putri, M. R. (2012). Pengaruh Durasi dan Intensitas Upwelling Berdasarkan Anomali Suhu Permukaan Laut terhadap Variabilitas Produktivitas Primer di Perairan Indonesia. Jurnal IImu dan Teknologi Kelautan Tropis, Vol. 4(1):6679.

Kunarso, Hadi, S. \& Ningsih, N. S. (2005). Kajian Lokasi Upwelling untuk Penentuan Fishing Ground Potensial Ikan Tuna. Jurnal IImu Kelautan, Vol.10(2):61-67.

Liu, C. C. \& Jin, Q. (1995). Artificial Upwelling in Regular and Random Waves. Ocean Engineering Journal. 22(4):337-350

Ningsih, N.S., N. Rakhmaputeri \& Harto, A.B. (2013). Upwelling Variability along the Southern Coast of Bali and in Nusa Tenggara Waters. Ocean Science Journal, 48(1):49-57.

Penven, P., Roy, C., Brundrit, G. B., Verdiere, A. C., Freon, P., Johnson, A. S., Lutjeharms, J. R. E., \& Shilington, F. A. (2001). A Regional Hydrodynamic Model of Upwelling in the Southern Benguela. South African Journal of Science 97:1-4.

Pranowo, W.S., Dewi, L. C., Mustikasari, E. \& Subki, B. A. (2010). Verification the model which using by the Government of Indonesia for oil spill model simulation - The claim document of October 2010. Suppl. Technical Report. Negotiation meeting between Gol \& PTTEP AA (Montara), Singapore, December 17-19, 2010, 8 pp.

Puti, C., Hadi, S. \& Pranowo, W. S. (2006). Study variability of thermocline layer and its relationship with the sea surface chlorophyll-a blooming condition in Ombai Strait and Savu Sea. Proceed. Workshop INSTANT, 12 September 2006, Jakarta.
Setiawan, A., Fitria Maharani,I., Riandini, F., (2007). Modul Pelatihan Penggunaan Software Pengolahan Data Oseanografi, Institut Teknologi Bandung. Bandung.

Sunarto, (2008). Peranan Upwelling terhadap Pembentukan Daerah Penangkapan Ikan. Karya IImiah. Fakultas Perikanan dan IImu Kelautan. Universitas Padjadjaran. Bandung.

Susanto, R. D., Gordon, A. L. \& Zheng, Q. (2001). Upwelling along the coasts of Java and Sumatra and its Relation to ENSO. Geophysical Research Letters. 28(8):1599-1602

Simbolon, D.F. \& Tadjuddah. T. (2008). Pendugaan Front dan upwelling melalui Interpretasi Citra suhu permukaan laut dan Clorofil-a di Perairan Wakatobi Sulewesi Tenggara. Bulletin PSP. Jurnal IImiah Teknologi dan Manajemen Perikanan Tangkap. Diterbitkan atas kerjasama Forum Komunikasi Kemitraan Perikanan Tangkap (FK2PT) dan Departemen Pemanfaatan Sumberdaya Perikanan Fakultas Perikanan dan IImu Kelautan. IPB Volume XVII.No.3 Hal.297384. Desember 2008. 